\title{
SOME METEOROLOGICAL ASPECTS OF DROUGHT
}

\section{WITH SPECIAL REFERENCE TO THE SUMMERS OF 1952-54 OVER THE UNITED STATES}

\author{
JEROME NAMIAS \\ Extended Forecast Section, U. S. Weather Bureau, Washington, D. C. \\ [Manuscript Received August 4, 1955]
}

ABSTRACT

\begin{abstract}
The problem of drought is examined as a manifestation of anomalous patterns of the atmosphere's general circulation. Special consideration is given to the quasi-stationary planetary wave ensembles which are responsible for extensive summertime drought over the United States. The critical importance of the great Atlantic and Pacific anticyclones for encouraging or discouraging the development of the great North American upper level anticyclone, the immediate drought producing cell, is emphasized.
\end{abstract}

\section{INTRODUCTION}

The term drought has never been given a quantitative definition acceptable to everyone. In loose terms it is an extended period characterized by lack of precipitation, the consequence of which is generally reflected in some important phase of the changing economy. Under this definition dry spells in areas at times when little or no rain normally falls are not considered drought periods, and the anomalous character of precipitation is an important part of the definition. It is this phase of the subject which shall be discussed in this article with particular emphasis on the departures of precipitation from long-term normals (the climatic anomalies of precipitation) as they relate to the atmosphere's broad-scale or general circulation.

Although forever attempting to approach some sort of equilibrium the atmosphere's circulation is never at rest. On a grand scale it has various modes of operation so that during a particular month the air currents composing the circulation may assert themselves in a similar manner on many days of the month. In this way the patterns of air flow have prevailing characteristics and these may be brought to light by averaging weather maps over the entire month. Such a chart for the month of October 1952 is shown in figure 1, where the averaging process has by no means damped out the planetary waves.

\section{CONDITIONS LEADING TO DROUGHT DURING MONTHS OTHER THAN SUMMER}

If the arrangement of planetary waves of the general circulation were to remain stationary those areas ahead of the troughs would receive bountiful precipitation while those behind the troughs and in the ridges would, because of the lack of precipitation-producing cyclones, be dominated by dry conditions leading perhaps to drought. This relationship between precipitation and planetary wave, well known and demonstrable statistically [1], results from the prevailingly upward motion of the air in advance of the midtropospheric troughs and the sinking motion behind. It is also associated with the development and movement of polar front waves ahead of the upper level trough.

While the planetary waves are never exactly stationary from day to day there are cases in which the broad-scale pattern remains quite similar for several days at a stretch and at times for as long as a fortnight or more. Such a case is illustrated by the conditions observed during October 1952 (fig. 1) which on a countrywide basis was the driest month ever observed in the history of the U. S. Weather Bureau [2]. From the resultant pattern of upper air flow for the month, in which the resultant winds blow parallel to the average contours shown in figure 1, it is apparent that most of the United States lay under the domination of either a strong ridge or a prevailing flow of air from the northwest. The troughs in which the storms were spawned and then steered northeastward were well off the Pacific Coast and along the Atlantic Coast. This particular pattern effectively shunts precipitation-producing storms away from the entire United States and also provides an efficient mechanism for inhibiting the influx of moist rain-bearing air masses from the Gulf of Mexico. Note that only Florida was materially affected by these air masses.

In a similar manner extensive dry (or wet) periods may be created over large areas, providing the basic pattern of upper level flow has a more or less characteristic geographical preference. It turns out that the day-to-day stability of the planetary wave pattern during October 1952 was much greater than is usually observed, or in 

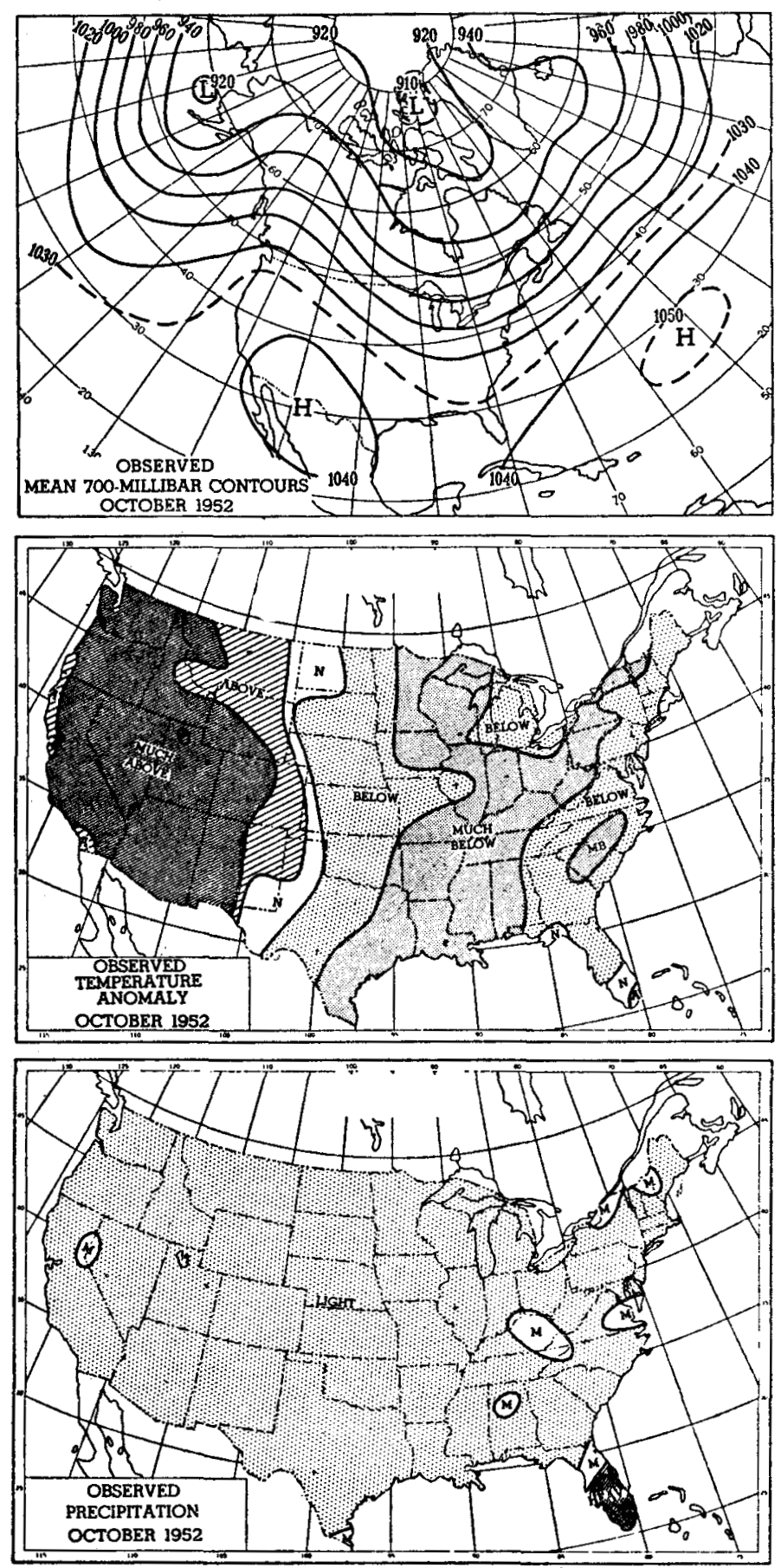

FigdRe 1.-(Top) Average 700-mb. height contours (labeled in tens of feet), October 1952. The average or resultant air flow blows parallel to the contours with lower heights to the left of the flow. (Middle) Classes of temperature departures from normal for October 1952. (Bottom) Classes of precipitation observed in October 1952, the driest month ever recorded in the United States. (Light, moderate, and heavy refer to terciles computed from many years of past Octobers.)

other words, the planetary wave patterns possessed remarkable persistence from day to day and even from week to week. The more common case is for the basic pattern to break down (or change) completely for a brief period (perhaps a few days or a week) only to reemerge and persist later on. The latter phenomenon is not so much a persistence of pattern as a persistent recurrence which thereby provides a bias in monthly (or longer period) averages of both flow pattern and associated meteorological elements.

Thus the central problem of drought revolves around the fact that it is a manifestation of certain recurrent forms of the general circulation, and therefore its prediction demands a fuller understanding of the mechanics of the general circulation.

\section{SUMMERTIME DROUGHT}

Precipitation deficiencies over intracontinental areas of temperate latitudes during summer are apt to have serious consequences on the economy. This is because a good proportion of the normal annual rainfall occurs in these areas at this time of year and because high temperatures then, usually associated with lack of rain, cause desiccation. The resulting effects on crops, livestock, and water supply in general are well recognized.

The atmospheric general circulation during summer drought has a quite characteristic pattern, and here again this pattern is brought into sharpest focus at levels well removed from the surface. In the normal course of transition from winter to summer the prevailing westerlies of temperate latitudes migrate northward. The jet stream with its planetary waves also engages in this migration. The magnitude of the shift is of the order of $10^{\circ}$ of latitude from about $30^{\circ} \mathrm{N}$. latitude in winter to $40^{\circ} \mathrm{N}$. latitude in summer. South of the crests of the planetary waves the belt of light wind flow and higher pressure fractures into great cells around which the air rotates in a clockwise manner. These cells are frequently the upper level components of the subtropical Highs at the surface, although over continents the surface anticyclone may be absent.

The air comprising these upper level cells comes largely from the prevailing westerlies to the north and slowly subsides to lower elevations [3]. In sinking, the air masses are warmed by compression, and consequently, the areas underlying these cells are characterized by abnormal warmth and by lack of clouds and rainfall.

The drought of 1936 may serve as an example. In figure 2 is shown the average pattern of flow at the 700-mb. level for August of that year and the associated departures from normal of temperature, while the corresponding departures of rainfall are shown in the inset of figure 3 . In figure 2 it may be noted that over lower latitudes there is a great girdle of high pressure which consists of several cells. One of these overlies southern United States and is associated with temperatures averaging as high as $10^{\circ}$ above seasonal normals in Missouri and Kansas, along with deficits of rainfall of from 2 to 4 inches over a broad area. Figure 3 shows the moisture characteristics of the prevailing air currents affecting the drought area during this month. This chart is not constructed for a constant level, but rather for an isentropic surface, along which air parcels are more or less constrained to move. Dry currents emanat- 

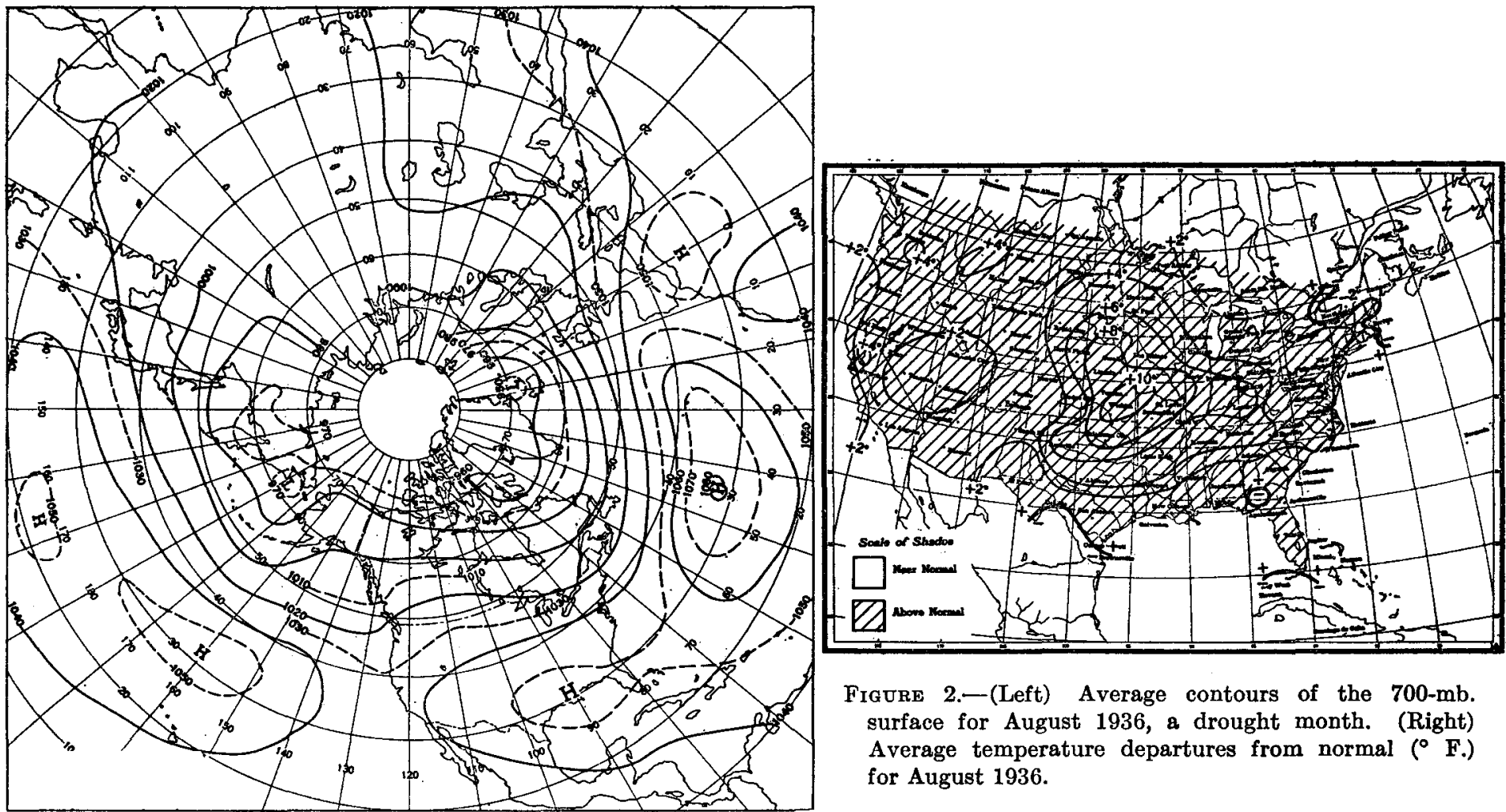

Figune 2.-(Left) Average contours of the 700-mb. surface for August 1936, a drought month. (Right) Average temperature departures from normal ( ${ }^{\circ} \mathrm{F}$.) for August 1936.

ing from high levels over Canada crossed the Great Lakes, flowed along and off the Atlantic Seaboard into Florida, and then spiraled into the anticyclonic cell over the Gulf States, subsiding gradually in transit [3]. Moist tongues of air arriving from the western Gulf of Mexico and the western Plateau were rapidly depleted of their moisture by being cut off and mixed with the flanking drier air currents.

Explanations of summertime drought hinge in large part on the position, extent, and development of these upper level semipermanent anticyclonic cells. This will be made clearer by discussion of the recent period of drought during the summers of 1952 through 1954 .

\section{SUMMER DROUGHT OF 1952-54}

During the summers of $1952-54$ the prevailing patterns of large-scale air flow and the resulting patterns of temperature and precipitation over the United States were quite similar. Therefore average charts constructed for the three summers, based on Junes, Julys, and Augusts of these years, effectively bring out the dominant characteristics of the triennium. The temperature and precipitation departures for the country shown in figure 4 illustrate the prevailingly hot and dry nature of south central portions.

The average pattern of air flow at the $700-\mathrm{mb}$. level for the three summers is shown in figure 5 by light solid lines. From these it is apparent that a great anticyclonic cell once more dominated south central United States and that other similar cells were located over the adjacent oceans.
Since drought is an abnormal phenomenon we are interested not only in the broad-scale patterns of air flow with which it is associated, but also in the anomalous character of this flow. One effective means of portraying this is by subtracting from the drought-producing pattern the normal pattern, as has been done in figure 5 . The heavy broken lines thus represent departures from normal of the height of the 700-mb. surface during the three summers of 1952-54. As with the contours, the prevailing anomalous component of the upper air flow may be deduced by noting that it flows parallel to the heavy broken lines in the sense that higher values always lie to the right of the anomalous flow. Thus the prevalence of much more than normal easterly and northeasterly flow along the Gulf Coast, inhibiting the northward penetration of deep moistureladen air masses from the Gulf of Mexico, is clearly shown.

The anomalous areas shown by the broken lines also illustrate other interesting features. For example, two large positive anomalies also suggestive of dryness appear over the central Pacific and central Atlantic. On the other hand the negative centers over Western Europe and northwestern United States were associated with prevailingly wet and cool weather.

The positive anomalies over the oceans are of a special importance because they deserve a good deal of the blame for the drought associated directly with the anomalous cell over the United States. The reason for this is that component parts of the planetary wave system, including the subtropical high pressure cells to the south of the wave crests, are not independent of one another but are interdependent [4]. That is, each cell has an influence on each 


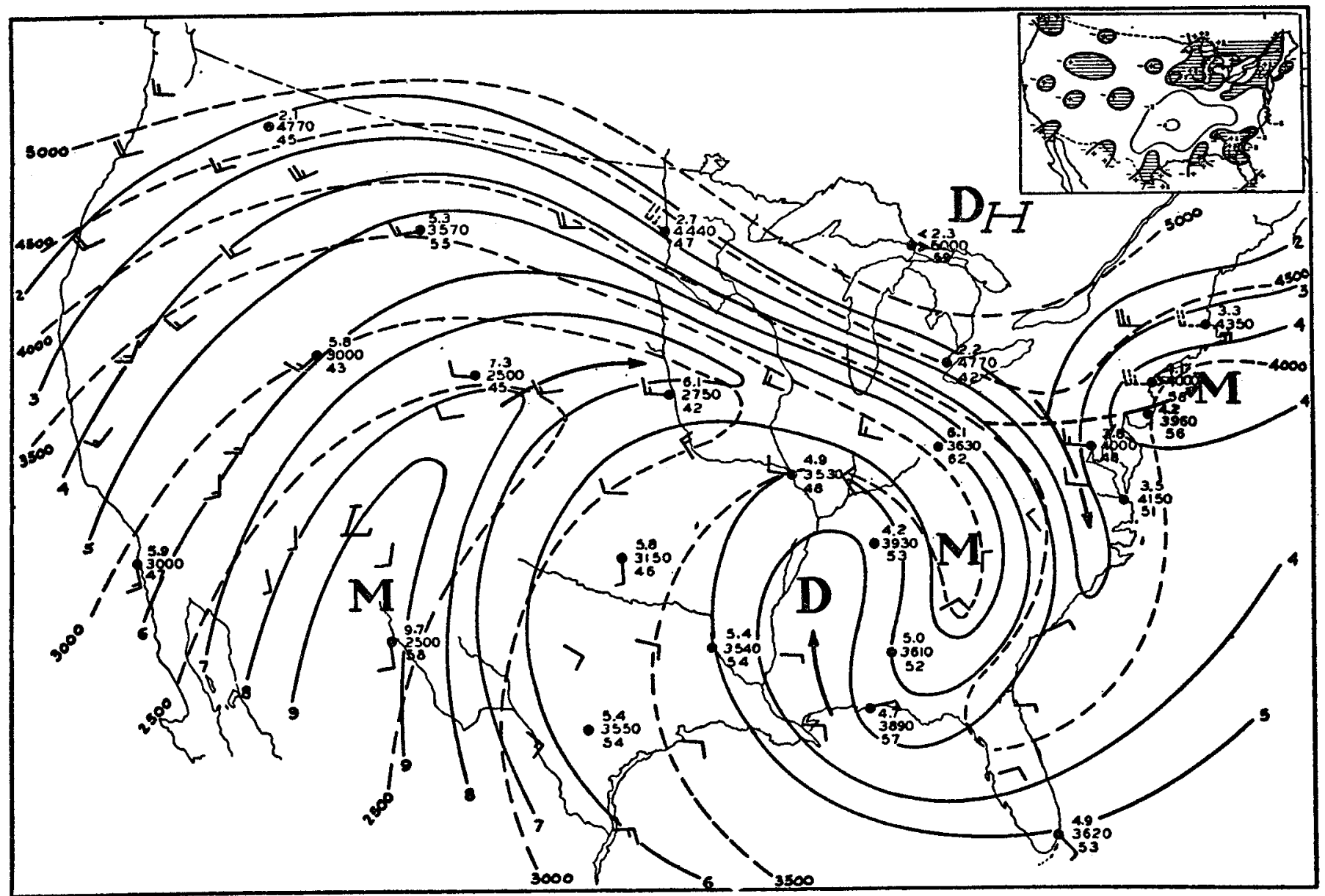

Figure 3.-Mean isentropic chart for the potential temperature surface $315^{\circ}$ A. for August 1936 . Height contours (broken lines) are labeled in meters above sea level. The average moisture content of the air at this surface (in $\mathrm{g} / \mathrm{kg}$ ) is shown by solid lines. Moist and dry tongues are labeled $M$ and $D$. Inset shows the departure from normal of precipitation in inches.

other cell of the hemisphere. Stable wave lengths of the planetary waves depend upon complex dynamical and thermodynamical effects induced largely by underlying terrain. If for some reason a certain disturbance in the westerlies is constantly being generated in one area, the absolute vorticity of air columns leaving this area will set up certain resonant features of flow in other, even remote, areas. In this manner disturbances formed in various areas may be reinforcing or conflicting, both in the regions at the seat of the disturbances and also in areas between. Since the present state of meterological theory is inadequate to tell very much about these influences over time intervals of more than a day or two, empirical work has been necessary to substitute for physical understanding.

One of these empirical approaches [5] has been to select from past years those average maps (in this case 700-mb. maps for 5-day periods) characterized in a certain season by a large positive or negative anomaly in a given area. One may then determine the probability of sign of anomaly, positive or negative, in other areas of the hemisphere, adjacent to and remote from the selected area. When this has been done a chart like figure 6 results. The selected area of positive anomaly in this figure is hatched and lines of equal probability of sign are drawn for each 10 percent. For example, figure 6 indicates that when a positive anomaly center appears in the hatched area in summer there is a probability of over 80 percent that the accompanying anomaly will be negative over much of the State of Washington and over 70 percent that it will be positive over New England. It may be demonstrated statistically that higher probabilities usually go with higher mean values of the anomaly itself, so that, in a general sense, isolines of probability may be interpreted similarly to isolines of anomaly.

From figure 6 it is clear that the Pacific cell of positive anomaly has a resonance effect over the United States which accounts for some of the features observed in the 1952-54 pattern. But the Pacific cell is only one of the influences which may affect the United States cell. Since the Atlantic cell is equally prominent in figure 5 , having a +10 anomaly, another probability chart similar to figure 6 but selected for the location of the Atlantic cell was used (not reproduced). A mean of the two probability charts based on Atlantic and Pacific fixes was prepared in order to capture the resonance effects of both Atlantic 

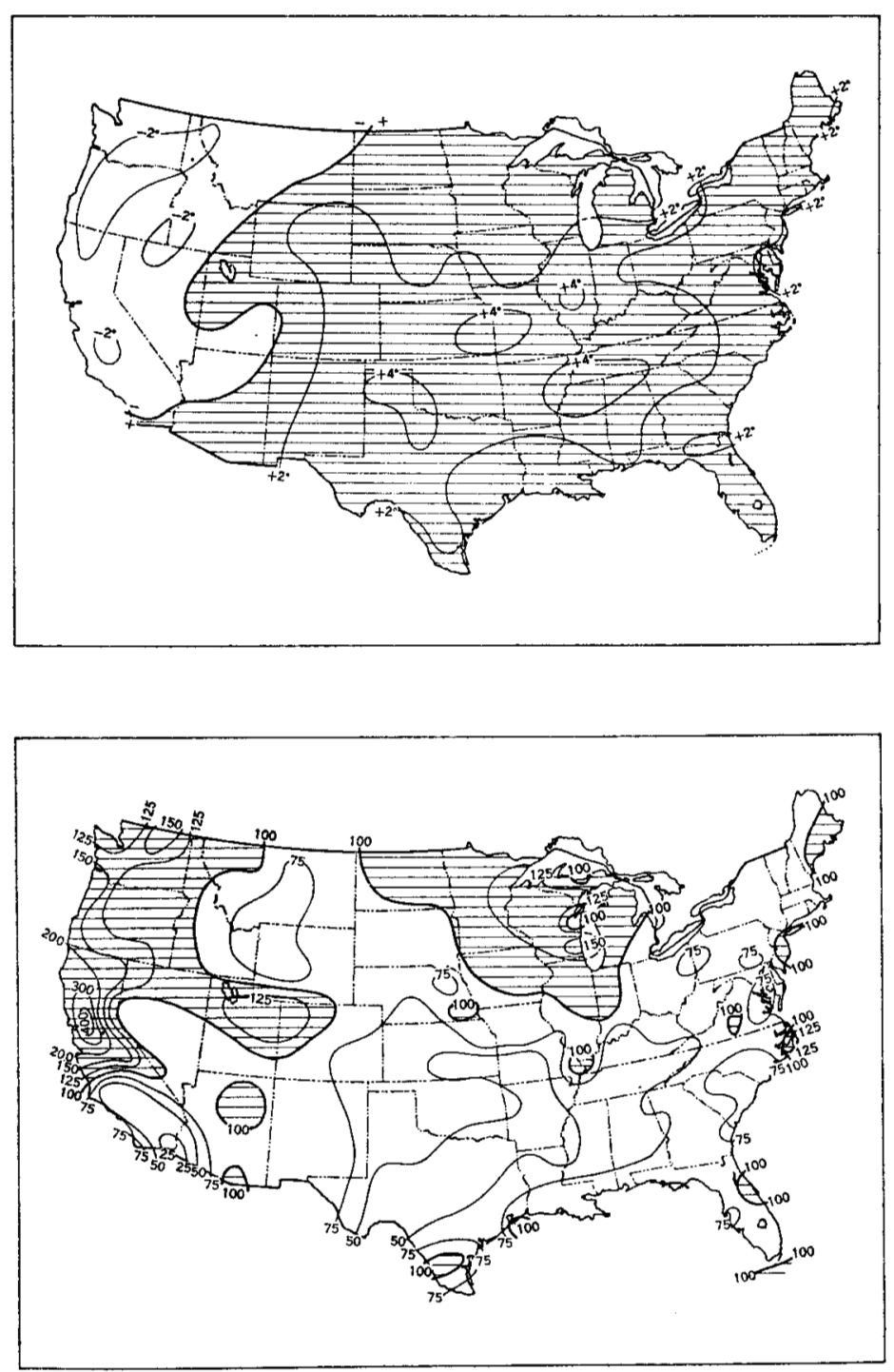

FIGURE 4.-(Top) Average temperature departures from normal ( ${ }^{\circ}$ F.) for the three drought summers (June, July, and August) of 1952-54. (Bottom) Percentage of normal precipitation for the summers 1952-54.

and Pacific on the North American pattern, and this combined chart is shown in figure 7. It is obviously not surprising to find similarity in pattern over the oceans in figures 7 and 5 , for these areas constituted the basis of selection. On the other hand the similarity of pattern over North America is indeed striking, since the data there are entirely independent. This correspondence indicates that the great drought-producing cell for the summers of 1952-54 needed for its sustenance companion cells in both Atlantic and Pacific.

\section{CONTRAST WITH PRECEDING 3 YEARS, 1949-51}

During 1949-51 the summertime weather and circulation regimes over the United States were quite different from those during the subsequent three summers. The contrasting precipitation regimes are shown in figure 8 , where the areas affected by drought in the later 3 years, were actually abnormally wet in the summers of 1949-51.

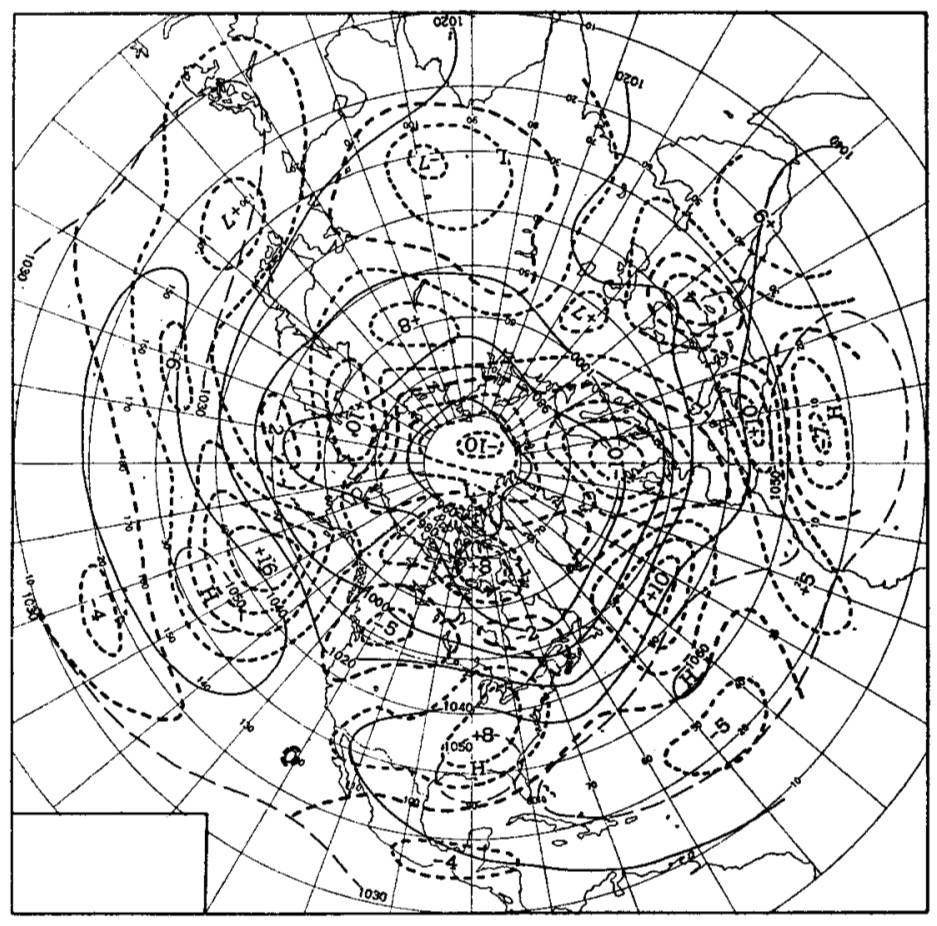

Figure 5.-Mean contours of $700-\mathrm{mb}$. height (solid) and lines of equal height departure from normal (broken) for the three summers 1952-54.

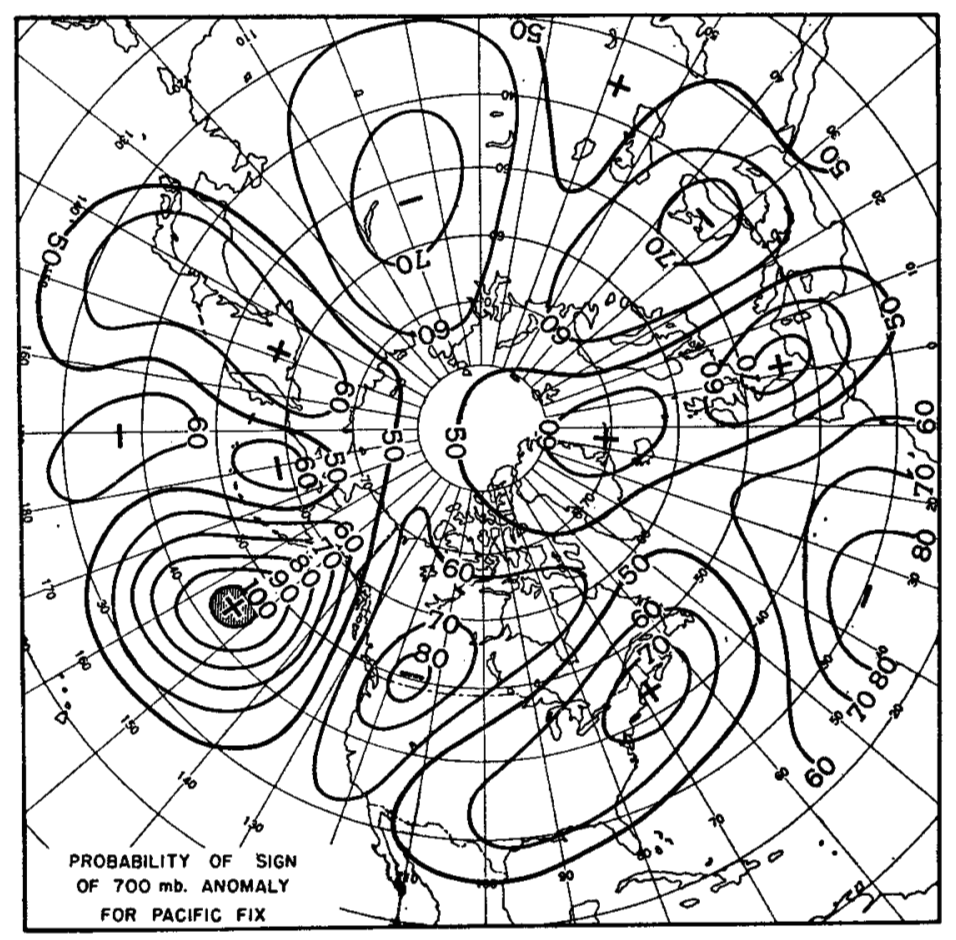

Frgure 6.-Probability of sign of $700-\mathrm{mb}$. height anomaly when an axis of positive anomaly lies in the vicinity of the hatched area in the Pacific in summer. (From [5].)

The patterns of circulation (fig. 9) were also materially different. In 1949-51 no strong anticyclonic cell or positive anomaly was present over the Gulf States. Anomalous northerly flow from Canada entered the Great Plains to converge with southerly transported Gulf air, 


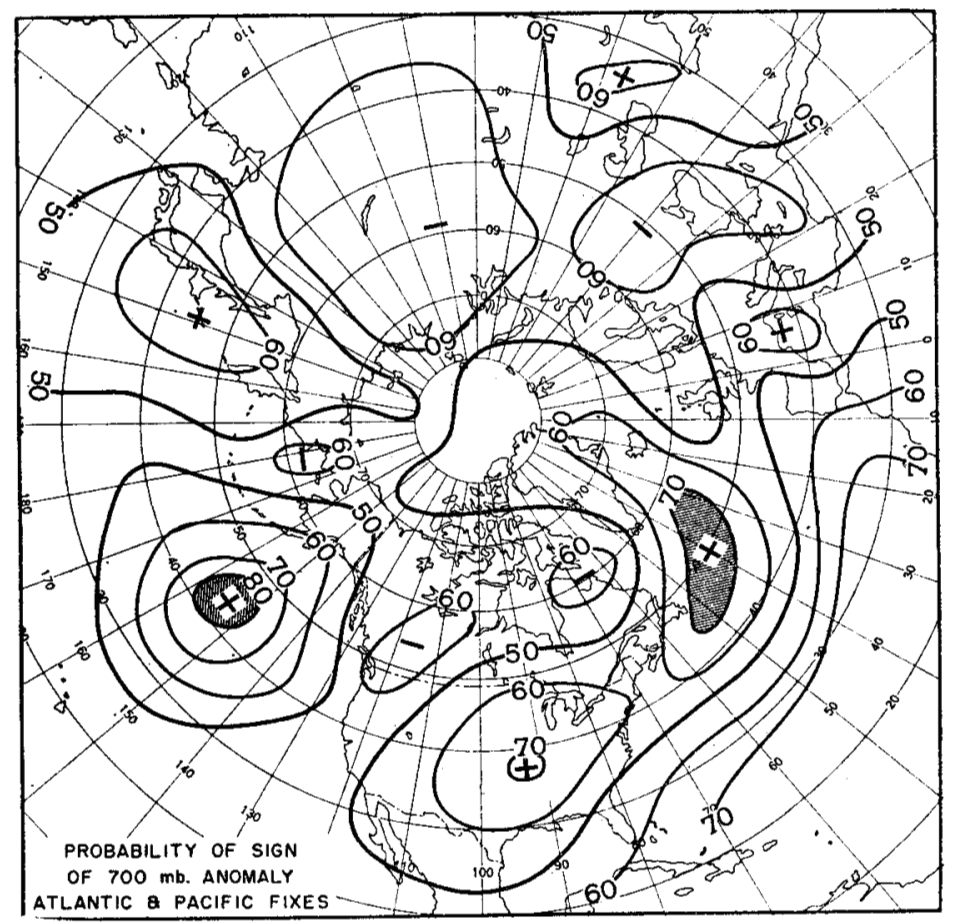

Figdre 7.-Probability of sign of $700-\mathrm{mb}$. height anomaly when axes of positive anomaly lie in the vicinity of the hatched areas shown in the Pacific and Atlantic in summer. (This is a mean of chart shown in fg. 6 and chart selected for positive anomaly in Atlantic. Both from [5].)

producing substantial frontal rains. The Northeast, dominated by the largest positive anomalies, had subnormal precipitation.

Perhaps the most interesting contrasts of figures 5 and 9 lie in the anomalies over the oceans. While the Pacific positive anomaly was present in 1949-51 much as in 1952-54, the Atlantic cell was entirely absent, and was replaced by a broad negative area. Apparently in sustaining the United States drought-producing cell the Atlantic positive cell is as important as the Pacific!

\section{POSSIBILITIES OF DROUGHT PREDICTION}

Inasmuch as drought-producing mechanisms are intimately tied to the general hemispheric circulation of the atmosphere it seems clear that correct predictions of this circulation should be the first goal for which to strive. Methods which show a moderate degree of success have been developed for 5- and 30-day periods. The latter predictions for example, were quite successful in catching the initiation of the 1953 and 1954 summer drought patterns as well as the October 1952 pattern shown in figure 1.

These 5- and 30-day forecasts are based largely upon long-period trends observed in series of average charts for upper atmospheric levels, upon the expected influences of
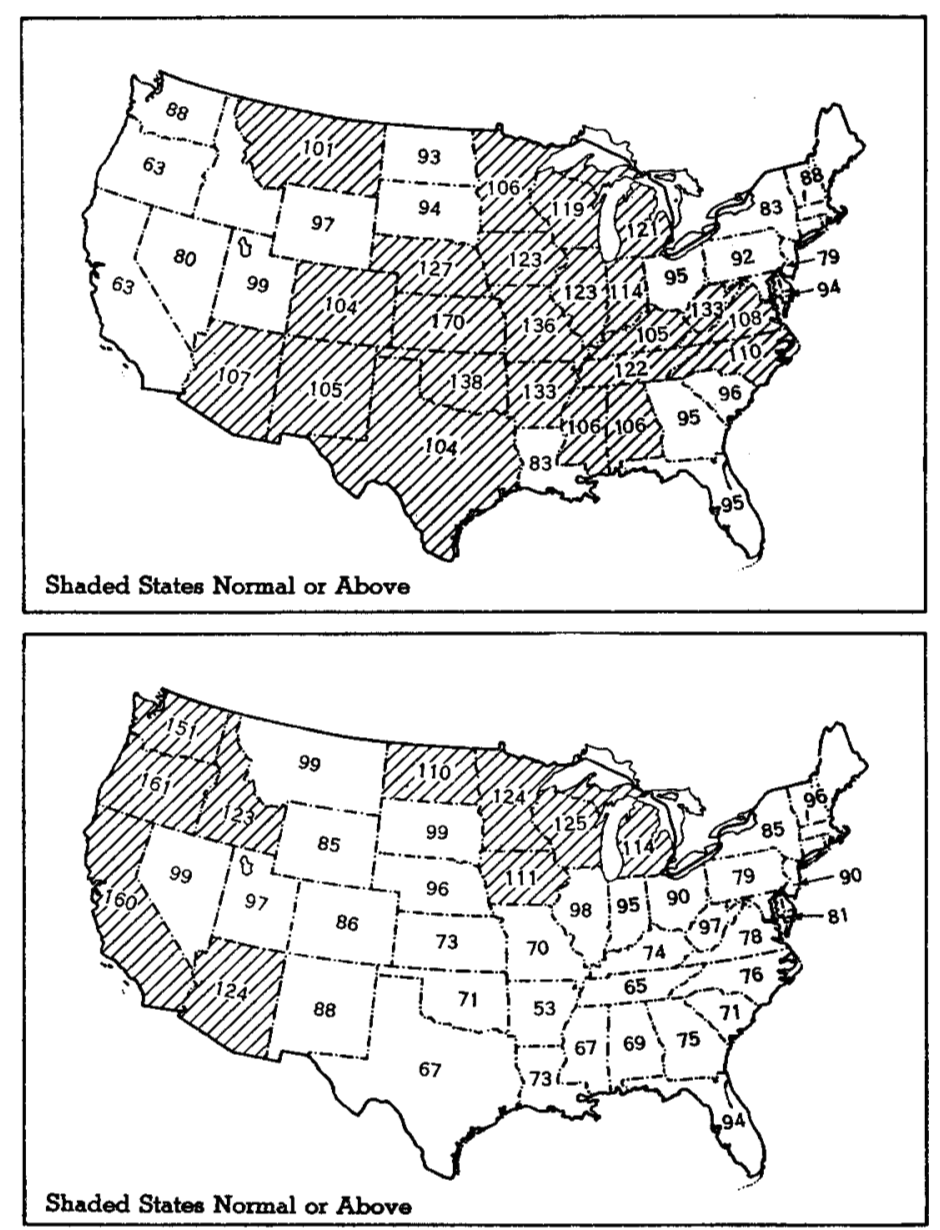

Frgure 8.- Percentage of normal precipitation by States for the summers of 1949-51 (top) and 1952-54 (bottom).

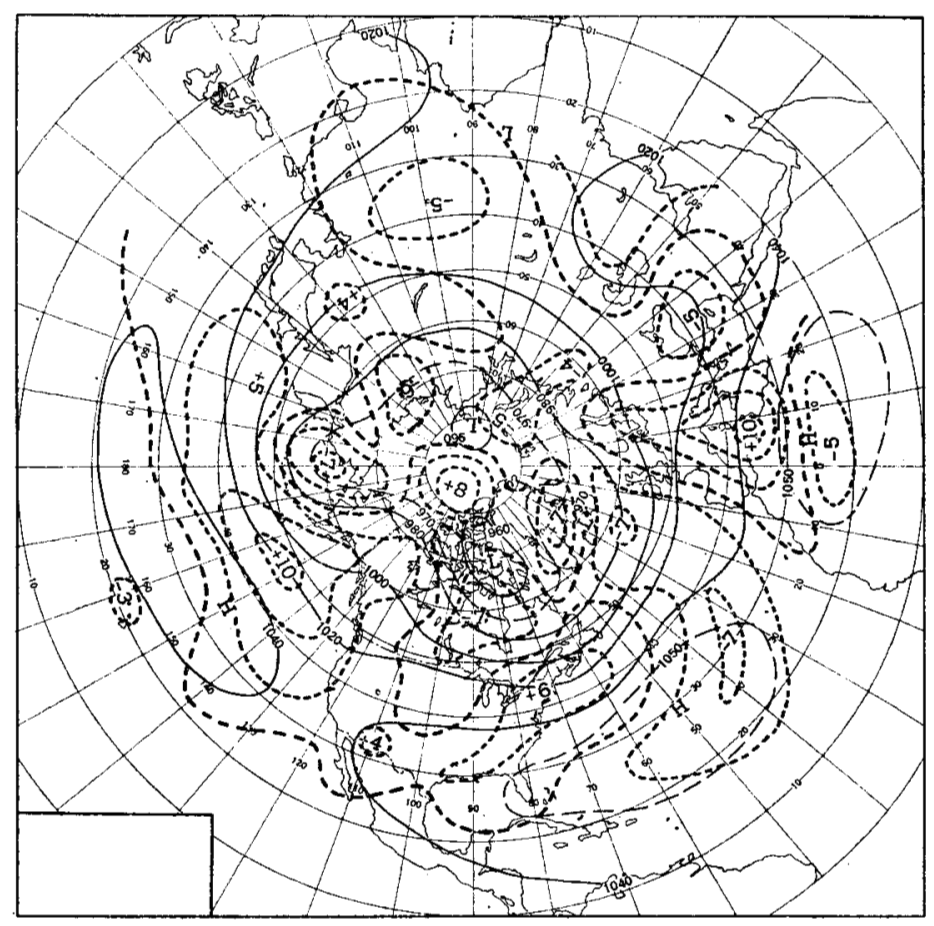

Frgure 9.-Mean contours (solid) of the $700-\mathrm{mb}$. surface and its departure from normal (broken) for the three summers 1949-51. 
seasonal transitions on these trends, upon empirical studies showing the mutual influences of each component of the circulation on its neighbors, and finally upon studies relating average weather to such average circulations [6].

In this methodology no direct account is taken of the detailed physical aspects of how or why such persistent features are established, for the simple reason that no one yet knows much about these fundamentally important topics. To name only a few pertinent factors, one might cite the differing effect of various surfaces (snow cover, open water, bare land, etc.) upon incoming radiation from the sun, the impact upon various air flows of mountain chains, and the net result of the latent heat of condensation released when precipitation falls. These factors presumably operate differently depending upon the initial state of the general circulation. In this sense subsequent anomalous patterns are viewed as a natural evolution from preceding patterns which are themselves anomalous. In other words, the circulation changes, whether treated on the scale of a day, a week, a month, a season or more, are self-evolving and are guided by an ever-changing radiational balance incident to changing season.

Another school of thought holds that the anomalous states of the general circulation are due to extraterrestrial causes. The more common hypotheses of this sort assume that the irregular variations in character of the sun's radiation, associated perhaps with sunspots, in some unexplained manner create certain patterns of the general circulation favorable or unfavorable for regional drought.

Although extensive studies of the above nature are proceeding in scientific institutions all over the world, and have been since before the turn of the century, no one has as yet uncovered the secret of long-period drought prediction. Now that hemispheric upper-air data are becoming reasonably extensive and a backlog of many years is accumulating, now that solar science and geophysical sciences like oceanography are being greatly expanded, there is greater hope than ever that a general solution to the drought problem may be forthcoming.

\section{REFERENCES}

1. W. H. Klein, "An Objective Method of Forecasting Five-Day Precipitation for the Tennessee Valley," U. S. Weather Bureau Research Paper No. 29, Washington, D. C., April 1949, 60 pp.

2. J. S. Winston, "The Weather and Circulation of October 1952-the Driest Month on Record in the United States," Monthly Weather Review, vol. 80, No. 10, Oct. 1952, pp. 190-194.

3. H. Wexler and J. Namias, "Mean Monthly Isentropic Charts and Their Relation to Departures of Summer Rainfall," Transactions, American Geophysical Union 19th Annual Meeting, April 1938, Part 1, pp. 164-170.

4. C.-G. Rossby, and collaborators, "Relation Between Variations in the Intensity of the Zonal Circulation of the Atmosphere and the Displacements of the Semi-Permanent Centers of Action," Journal of Marine Research, vol. 2, No. 1, Jan. 1939, pp. 38-55.

5. D. E. Martin, Anomalies in the Northern Hemisphere 700-mb. 5-day Mean Circulation Patterns, 1953, AWSTR 105-100, Air Weather Service, U. S. Air Force (to be published).

6. J. Namias, "Thirty-Day Forecasting: A Review of a Ten-Year Experiment," Meteorological Monographs, vol. 2, No. 6, American Meteorological Society, Boston, 1953, 83 pp.

Detailed treatment of the average monthly characteristics of the weather and circulation during the droughtdominated summers of 1952-54 may be found in articles by Winston, Klein, and Hawkins in appropriate issues of the Monthly Weather Review. 